\title{
Low bandgap GaInAsSb thermophotovoltaic cells on GaAs substrate with advanced metamorphic buffer layer
}

Qi Lua ${ }^{a^{*}}$, Richard Beanland ${ }^{b}$, Denise Montesdeoca ${ }^{a}$, Peter J. Carrington ${ }^{c}$, Andrew Marshall ${ }^{a}$, Anthony Krier $^{\mathrm{a}}$

a Physics department, Lancaster University, Lancaster, LA1 4YB, United Kingdom

${ }^{\mathrm{b}}$ Department of physics, University of Warwick, Coventry, CV47AL, United Kingdom

${ }^{c}$ Engineering department, Lancaster University, Lancaster, LA1 4YW, United Kingdom

* Correspondence

Qi Lu, Physics department, Lancaster University, Lancaster, LA1 4YB, UK.

E-mail: q.lu3@lancaster.ac.uk 


\begin{abstract}
Thermophotovoltaic (TPV) devices based on GaInAsSb lattice matched to GaSb (100) substrates have demonstrated high external quantum efficiencies (EQEs) in the mid-infrared spectral range, making them promising candidates for waste heat recovery from high temperature "blackbody" sources. In this work, the GaInAsSb alloy has been integrated onto more cost-effective GaAs (100) substrates by using advanced metamorphic buffer layer techniques in molecular beam epitaxy (MBE), which included an interfacial misfit (IMF) array at the $\mathrm{GaSb} / \mathrm{GaAs}$ interface followed by $\mathrm{GaInSb} / \mathrm{GaSb}$ dislocation filtering layers. The threading dislocations in the GaInAsSb region can be efficiently supressed, resulting in high quality materials for TPV applications. To determine the performance of the GaInAsSb TPV on GaAs it was compared with a cell grown lattice matched onto GaSb substrate having the same structure. The resulting TPV on GaAs exhibited similar dark current-voltage characteristics with that on GaSb. Under illumination from an $800{ }^{\circ} \mathrm{C}$ silicon nitride emitter, the short circuit current density $\left(\mathrm{J}_{\mathrm{sc}}\right)$ from the GaInAsSb TPVs on GaAs reached more than $90 \%$ of the control cell on GaSb, and the open circuit voltage $\left(\mathrm{V}_{\text {oc }}\right)$ exceeded $80 \%$ of the cell on GaSb. The EQE from the TPV on GaAs reached around $62 \%$, the highest value reported from this type of TPV on GaAs. With improved TPV structure design, large area GaInAsSb TPV panels on GaAs substrates can be realized in the future for waste heat energy recovery applications.
\end{abstract}

\title{
KEYWORDS
}

Thermophotovoltaics, GaInAsSb, dislocation filtering, interfacial misfit array 


\section{Introduction}

Using the same working principle as solar cells, thermophotovoltaic (TPV) cells can absorb the emitted photons from "blackbody" thermal sources to produce current flow and voltage bias, providing a direct and convenient energy conversion method from heat to electricity [1,2]. With the advantages of a fully solid state process, wide absorption spectra and direct DC power output, TPVs can find a variety of applications such as large and microscale power generators [3], solar thermophotovoltaics [4], remote or silent power and alternative power supply in space applications [5]. Moreover, TPV systems can also be designed to absorb the thermal radiation from existing high temperature sources, which are prevalent in many industrial sites, serving as a waste heat recovery technique. For example in steel, glass and cement factories where temperatures can reach above $1000 \mathrm{~K}$ on the production line [6]. The installation of efficient TPV systems in these places could generate additional electricity to power some of the on-site equipment, helping to reduce the overall energy consumption and carbon emissions.

In the last few decades, different semiconductor materials such as silicon [7], InAs [8], InGaAs [9], GaSb [10,11] and GaInAsSb [12-15] have been investigated for TPV cell applications. Among these, the GaSb TPV cells with bandgap $\sim 0.72 \mathrm{eV}$ have achieved more than $0.5 \mathrm{~V}$ open circuit voltage $\left(\mathrm{V}_{\mathrm{oc}}\right)$ and more than $60 \%$ external quantum efficiency (EQE). In addition, a number of commercial designs for the GaSb based TPV power generators have been patented [16,17], making it the most mature TPV technology to date. However, simulation work indicated that for lower temperature 1000-1800 K thermal emitters, GaInAsSb TPVs can achieve much higher power conversion efficiencies than the GaSb TPVs, mainly due to the narrower bandgap of GaInAsSb enabling the cells to absorb more emitted photons $[18,19]$, although a more realistic consideration by Tang et. al. estimated that for devices with diffused emitters, the GaSb cell can surpass the GaInAsSb cell in output power when illuminated by a higher than $1500 \mathrm{~K}$ blackbody [20]. The work on GaInAsSb based TPVs has been mostly focused on $0.53 \mathrm{eV}$ bandgap $\mathrm{Ga}_{0.82} \mathrm{In}_{0.18} \mathrm{As}_{0.16} \mathrm{Sb}_{0.84}$ materials grown latticed matched on $\mathrm{GaSb}(001)$ substrates. Both molecular been epitaxy (MBE) and metal organic chemical vapor deposition (MOCVD) have been successfully utilized for the device growth. By optimizing the doping concentrations and carrier blocking layers, excellent performance from GaInAsSb TPVs have been reported with an $\mathrm{V}_{\mathrm{oc}}$ of around $0.3 \mathrm{~V}$, about 60\% EQE and 90\% internal quantum efficiency (IQE) [15].

Because GaSb substrates are expensive, at present this limits the applications of the GaInAsSb TPVs, especially for situations where large area panels are required, such as for waste heat recovery. By comparison, GaAs (001) substrates can provide a cost-effective III-V semiconductor material platform with mature processing techniques for the widespread utilization of GaInAsSb TPVs. However, the existing GaInAsSb TPV technology on GaSb cannot be directly transplanted onto the GaAs substrates due to the large lattice mismatch $\Delta \mathrm{a} / \mathrm{a}_{0}=7.8 \%$, where $\mathrm{a}_{0}$ denotes the lattice constant of GaAs and $\Delta \mathrm{a}$ the lattice constant difference. High densities of threading dislocations will result from the direct epitaxial 
growth of GaInAsSb onto GaAs, which seriously deteriorates the device performance [21,22]. Various metamorphic growth techniques have been investigated for the epitaxial integration of different types of semiconductors with large lattice mismatch, such as graded buffer layers [23], dislocation filtering structures [24] and interlayer structures [25]. However, little work has yet been carried out on the integration of GaInAsSb on GaAs substrates.

In this work, we designed an advanced metamorphic buffer layer structure by combining interfacial misfit (IMF) arrays [26] with dislocation filtering layers (DFLs), for the MBE growth of GaInAsSb TPVs on GaAs substrates. The strain release and the evolution of the threading dislocations in the buffer layer were studied using transmission electron microscopy (TEM) and geometric phase analysis (GPA). The dislocation density in the TPV region was obtained from electron channelling contrast images (ECCIs). The GaInAsSb TPV on GaAs was fabricated and studied together with a reference TPV having the same structure but grown lattice matched on GaSb. The electrical and optical properties of the TPVs were systematically measured and the performance of the TPV on GaAs was compared with the reference cell under the same test conditions. The metamorphic TPV on GaAs achieved very similar values of $\mathrm{V}_{\mathrm{oc}}, \mathrm{J}_{\mathrm{sc}}$ and $\mathrm{EQE}$ compared with the reference cell, demonstrating that efficient dislocation suppression in the buffer region can enable GaAs substrates as a low-cost platform for GaInAsSb TPV applications in the future.

\section{Experimental details}

2.1 Molecular beam epitaxy

A Veeco GENxplor solid source MBE system was utilized for the growth of the TPV structure on a 2inch silicon-doped GaAs (n) substrate with n-type carrier concentration of $10^{17} \mathrm{~cm}^{-3}$. Firstly, undoped $\mathrm{GaSb}(\mathrm{i}-\mathrm{GaSb}$ ) material was deposited on the GaAs substrate using the IMF technique at the $\mathrm{GaSb} / \mathrm{GaAs}$ interface, at $560{ }^{\circ} \mathrm{C}$ substrate temperature $\left(\mathrm{T}_{\mathrm{s}}\right)$. The $\mathrm{T}_{\mathrm{s}}$ was then lowered to $500{ }^{\circ} \mathrm{C}$ for the growth of about $1 \mu \mathrm{m}$ of GaSb. Four regions of DFLs were then deposited, each containing 10 periods of GaInSb $(10 \mathrm{~nm}) / \mathrm{GaSb}(12 \mathrm{~nm})$ and separated by $300 \mathrm{~nm}$ i-GaSb in between. The $\mathrm{T}_{\mathrm{s}}$ was maintained at $445{ }^{\circ} \mathrm{C}$ for the SL growth. The GaInAsSb material was calibrated to have the same lattice constant as $\mathrm{GaSb}$. With a bandgap of about $0.5 \mathrm{eV}$, the composition was estimated as $\mathrm{Ga}_{0.78} \mathrm{In}_{0.22} \mathrm{As}_{0.20} \mathrm{Sb}_{0.80}$ [27]. Based on previous work [13], the TPV was designed as a $p$-on- $n$ structure, with a 0.5 - $\mu \mathrm{m}$-thick GaSb $n$-contact layer doped to $5 \times 10^{17} \mathrm{~cm}^{-3}$ at the bottom, followed by a 1- $\mu$ m-thick GaInAsSb base region also $n$ doped to $5 \times 10^{17} \mathrm{~cm}^{-3}$, a $4-\mu \mathrm{m}$-thick GaInAsSb emitter region $p$ doped to $2 \times 10^{17} \mathrm{~cm}^{-3}$, and a $0.1-\mu \mathrm{m}$-thick GaSb contact/window layer $p$ doped to $2.5 \times 10^{18} \mathrm{~cm}^{-3}$. The thick $p$-emitter will serve as the major absorption region, which can take advantage of the longer minority carrier diffusion length in $p$-type GaInAsSb than in the $n$-type material. It is worth noting that in our current TPV structure, the wide bandgap barrier 
layer and back surface field (BSF) layer have not been included. The TPV structure together with the buffer region is illustrated in Fig. 1. An identical TPV was grown by MBE on a GaSb (n) substrate doped to $\sim 10^{17} \mathrm{~cm}^{-3}$ without the buffer region and used as the reference cell.

\subsection{Device processing}

The GaInAsSb TPV on GaAs and the reference cell were processed using conventional photolithography and wet etching techniques. The samples from MBE were dipped in $\mathrm{HCl}_{2} \mathrm{H}_{2} \mathrm{O}$ (1:1) solution to remove contaminants and surface oxidation. Circular mesas in $400 \mu \mathrm{m}$ diameter were fabricated on both samples by etching in a $\mathrm{H}_{3} \mathrm{PO}_{4}$ and $\mathrm{C}_{6} \mathrm{H}_{8} \mathrm{O}_{7}$ based solution. Afterwards, the sidewalls were cleaned by soaking the samples in $\mathrm{HCl}: \mathrm{H}_{2} \mathrm{O}: \mathrm{H}_{2} \mathrm{O}_{2}(100: 100: 1)$ to eliminate possible surface defects. The patterns of the metal contacts were defined by two layers of photoresist for the lift-off process. The p-contacts were made of $\mathrm{Ti}(20 \mathrm{~nm}) / \mathrm{Au}(200 \mathrm{~nm})$ and the $\mathrm{n}$-contacts consisted of GeAu $(20 \mathrm{~nm}) / \mathrm{Au}(200 \mathrm{~m})$, both of which were deposited by thermal evaporation. No anti-reflection (AR) coating was deposited on the devices. Fig. 1 illustrates the finished TPV device on GaAs.

\subsection{Characterization}

TEM specimens were prepared using standard grinding, polishing and $\mathrm{Ar}^{+}$ion-milling to electron transparency, and examined in JEOL $2100 \mathrm{LaB}_{6}$ TEM operating at $200 \mathrm{kV}$. GPA measurement was performed using the program Strain++, which is based on the strain analysis method proposed by Hÿtch et al. [28]. ECCI results were obtained with a Zeiss Gemini scanning electron microscope operating at $30 \mathrm{kV}$ and a 4-quadrant backscatter electron detector. In order to investigate the structural quality of the $\mathrm{SL}$ regions on GaAs, the GaInAsSb material was etched off and the underlying structure was examined using high resolution double crystal X-ray diffraction (XRD) measurements with a Bede QC200 diffractometer. The EQE of the cells were measured using a Bentham PVE300 system with a PbS detector. The current-voltage characteristics were measured using a Keithley 2400 source meter. The TPVs were mounted in front of an $800{ }^{\circ} \mathrm{C}$ silicon nitride $\left(\mathrm{Si}_{3} \mathrm{~N}_{4}\right)$ emitter or a solar simulator at 1 sun (AM1.5 condition) to determine the photo and electrical response. The $800{ }^{\circ} \mathrm{C} \mathrm{Si}_{3} \mathrm{~N}_{4}$ graybody emitter has a high emissivity of $\sim 0.9$ in $1-5 \mu \mathrm{m}$ spectral range [29], with peak wavelength $\lambda_{\mathrm{pk}} \sim 2.7 \mu \mathrm{m}$, while the solar simulator has $\lambda_{\mathrm{pk}} \sim 0.6 \mu \mathrm{m}$.

\section{Results and dis cussions}

\subsection{Metamorphic buffer layer}

The epitaxial growth of lattice mismatched materials is highly desirable so as to make use of cheaper and more mature substrate platforms such as GaAs and $\mathrm{Si}$. High densities of threading dislocations 
(TDs) can be excepted from the direct deposition of epilayers onto substrates with large lattice mismatch, which can significantly deteriorate the performance of most semiconductor devices. By simply growing thicker buffer layers one can reduce the TD density, but theoretical modelling predicts that if the TD density reduction cannot be efficient enough by the use of thick buffer layers alone [30]. Various approaches have been proposed for the reduction of TDs in highly mismatched semiconductors. Among them, the dislocation filtering layers (DFLs) which are composed of strained superlattices, have demonstrated efficient reduction of TD densities [31]. For example, DFLs have been successfully implemented in the MBE growth of III-V lasers [32] and photo-detectors [33] on Si substrates where they have achieved excellent performance. Besides the DFL technique, interfacial misfit (IMF) arrays have been developed, particularly for the growth of GaSb on GaAs. Subsequently, GaSb based lasers [34], light emitting diodes [35] and detectors [36] on GaAs with IMF arrays have been reported. Recently, GaSb TPVs have also been integrated on GaAs substrates using IMF techniques but exhibited an EQE of only 40\% [37]. The effect of IMF arrays has been extensively investigated. They can effectively release the strain in the direction perpendicular to the interface, thus reducing the number of TDs in the subsequent epilayers [26]. In our design, we combined the advantages of the IMF array, i.e. lower TD density arising from the $\mathrm{GaSb} / \mathrm{GaAs}$ interface, together with the DFLs, i.e. efficient reduction of the TD density in the buffer region, to achieve high quality lower bandgap GaInAsSb material on GaAs substrate for TPV applications.

Cross-section TEM images of the metamorphic buffer were shown in Fig. 2a. The IMF array on the $\mathrm{GaSb} / \mathrm{GaAs}$ interface shown in Fig. 2c was comprised of $1 / 2<110>$ edge misfit dislocations with a spacing of $\sim 3.7 \mathrm{~nm}$, which give $100 \%$ relief of the misfit strain and were clearly visible in the $\varepsilon_{x x}$ strain map produced by GPA (Fig. 2d). Interestingly, many of the dislocation cores were split in two in the GPA strain map, which may indicate that the misfit dislocations have dissociated into a pair of $1 / 4<110>$ dislocations on the (001) plane. Only a small fraction $(<1 \%)$ of these misfit dislocations turned into TDs, but this still resulted in high densities of TDs $\left(>10^{9} \mathrm{~cm}^{-2}\right)$, which can be observed originating from the region near the $\mathrm{GaSb} / \mathrm{GaAs}$ interface in Fig. 2a. Initially, the TD density decreased rapidly away from the interface, but after the first few hundred nanometer there was little obvious change. Consequently, we placed 4 DFL structures, separated by $\sim 300 \mathrm{~nm} \mathrm{GaSb}$, on top of the $1 \mu \mathrm{m}$ thick GaSb layer. Each DFL was composed of a strained superlattice of 10 periods of $\mathrm{GaInSb} / \mathrm{GaSb}$, designed to have strain above the critical thickness for relaxation with the aim of moving TDs laterally to encourage them to interact and annihilate. Fig. 2b showed the high resolution TEM image of the top DFL region, where clear interfaces between GaInSb and GaSb can be observed. Fig. 3 showed the $\omega$-2 $2 \theta$ XRD plot from the buffer after removal of the TPV by etching (red curve), together with the simulated fit (blue curve). The peak at zero was the GaAs substrate and the one at -9570 arcsec was the GaSb. The satellite peaks on both sides of the GaSb peak were generated by the superlattices. The simulation gave layer thicknesses in the superlattice of $\sim 10.1 \mathrm{~nm}$ for GaInSb and $\sim 11.5 \mathrm{~nm}$ for GaSb, very close to the 
designed values of $10 \mathrm{~nm}$ and $12 \mathrm{~nm}$ respectively. The composition of the strained ternary material can also be determined as $\mathrm{Ga}_{0.83} \mathrm{In}_{0.17} \mathrm{Sb}$. The measured XRD spectrum exhibited broader, weaker and fewer superlattice peaks in comparison with the simulated spectrum. These differences were caused by the misfit dislocations at the superlattice-matrix interface that form as they relax (Fig. 2a). Fig. 2a also exhibited a decreasing density of TDs through the DFL structure, such that the material above the top DFL region appeared dislocation free in the limited area observed by TEM. The mechanism of TD suppression by strained superlattices in GaAs buffers has been investigated in detail [30]. In the work of Chen et al. [24], $\mathrm{In}_{0.18} \mathrm{Ga}_{0.82} \mathrm{As} / \mathrm{GaAs}$ superlattices with a strain of $1.2 \%$ achieved excellent results on the reduction of TD densities. In our design, the $\mathrm{Ga}_{0.83} \mathrm{In}_{0.17} \mathrm{Sb} / \mathrm{GaSb}$ superlattices generated a strain of $1.1 \%$, almost same as in their work. Thus, in order to quantify the TD density in the active region we performed ECCI on the sample surface, which allowed even low densities of TDs to be observed by the effects of their strain fields on a backscattered electron image [38]. TDs appeared as bright or dark spots in the ECCI image of Fig. 4, with a density of $(6.0 \pm 0.8) \times 10^{6} \mathrm{~cm}^{-2}$, much better TD suppression than $\mathrm{GaSb} / \mathrm{AlSb}$ superlattices reported previously [39].

\subsection{Electrical characterization}

The dark current density-voltage (J-V) curves of the TPV on GaAs and the reference cell are plotted in Fig. 5a. Both devices were in $400 \mu \mathrm{m}$ diameter. In the forward bias regime, the two curves showed a very similar trend. The series resistance $\left(R_{s}\right)$ was estimated by making linear fit on the I-V curves in Fig. $5 \mathrm{a}$, on the part of the characteristic where the voltage was greater than $0.35 \mathrm{~V}$. The series resistancearea product $\left(R_{\mathrm{s}} \cdot A\right)$ of the TPV on GaAs $\left(49 \mathrm{~m} \Omega \cdot \mathrm{cm}^{2}\right)$ was smaller than the reference cell $\left(61 \mathrm{~m} \Omega \cdot \mathrm{cm}^{2}\right)$. However, the $\mathrm{R}_{\mathrm{s}} \cdot \mathrm{A}$ from our devices was still larger than the lowest reported experimental value $(\sim 15$ $\mathrm{m} \Omega \cdot \mathrm{cm}^{2}$ ) [40]. The top-top contact configuration in our devices can very possibly result in larger $R_{s} \cdot A$ compared with top-bottom contacts. In the future device design, thicker and more heavily doped ncontact layers may help reduce the series resistance. It is also evident from Fig. 5a that under reverse bias, the current density from the TPV on GaAs was close to, but still higher than that of the reference cell. At $-0.1 \mathrm{~V}$ bias, the dark current density from the device on $\mathrm{GaAs}$ reached $5.6 \mathrm{~mA} / \mathrm{cm}^{2}$, compared with $1.9 \mathrm{~mA} / \mathrm{cm}^{2}$ from the reference cell. The comparison between these two dark J-V curves confirms that the metamorphic buffer on GaAs has successfully reduced the TD density in the GaInAsSb TPV active region to a very low level, suitable for photonic device fabrication and very similar to the reference device on GaSb which was free of TDs caused by lattice mismatch. Since the structure and processing techniques of the two devices was the same, the higher reverse current density were mostly likely caused by the still remaining TDs in the TPV active region. They can act as non-radiative recombination centers and reduce the minority carrier lifetime [21], resulting in higher dark saturation current density $\mathrm{J}_{0}$ from the generation-recombination mechanism. Higher $\mathrm{J}_{0}$ has been reported from devices with higher TD densities [41]. 
Mesas of different sizes were also made from the same samples. The inverse of zero bias differential resistance-area product $\left(1 / \mathrm{R}_{0} \mathrm{~A}\right)$ versus perimeter to area ratio $(\mathrm{P} / \mathrm{A})$ from these two samples are shown in Fig. $5 b$. The $R_{0}$ was estimated from -10 to $10 \mathrm{mV}$ bias range on the $\mathrm{I}-\mathrm{V}$ curves. The $1 / \mathrm{R}_{0} \mathrm{~A}$ values from the devices on GaAs were close to, but still higher than the reference, possibly due to the TDs in the TPV on GaAs [42] The two linear fits shown by the dashed lines were not parallel to the $x$-axis, indicating that there were some weak size dependences for both structures. The sidewall resistivity, which equals the inverse gradient of the linear fit in Fig. $5 \mathrm{~b}$, can be estimated as $1.79 \mathrm{k} \Omega \cdot \mathrm{cm}$ for the sample on GaAs, compared with $2.84 \mathrm{k} \Omega \cdot \mathrm{cm}$ for the reference sample on $\mathrm{GaSb}$.

To characterize the TPV performance, the two cells were first mounted in front of an $800{ }^{\circ} \mathrm{C} \mathrm{Si}_{3} \mathrm{~N}_{4}$ emitter with a parabolic reflector (Hawkeye Technologies LLC, IR-18 infrared source). The J-V curves of the two TPVs in Fig. 6a exhibited very similar trends. The TPV on GaAs achieved a $\mathrm{J}_{\mathrm{sc}}$ of $0.98 \mathrm{~A} / \mathrm{cm}^{2}$, which was very close to the reference cell $\left(1.04 \mathrm{~A} / \mathrm{cm}^{2}\right)$. The $\mathrm{V}_{\text {oc }}$ from the TPV on GaAs was $0.178 \mathrm{~V}$, about $83 \%$ of the $\mathrm{V}_{\text {oc }}$ from the reference cell $(0.214 \mathrm{~V})$. The fill factor $(\mathrm{FF})$ was estimated to be $46 \%$ for the metamorphic TPV on GaAs and 53\% for the reference TPV. These two cells were also tested under a solar simulator at 1 sun (AM 1.5 condition), which generated the J-V curves shown in Fig. 6 b. The $\mathrm{J}_{\mathrm{sc}}$ from the TPV on GaAs $\left(0.035 \mathrm{~A} / \mathrm{cm}^{2}\right)$ reached about $87 \%$ of the reference cell $\left(0.040 \mathrm{~A} / \mathrm{cm}^{2}\right)$. Both these $\mathrm{J}_{\mathrm{sc}}$ values were slightly higher than the $\mathrm{J}_{\mathrm{sc}}$ from the GaSb TPVs under the same test conditions reported by Tang et al. [11], which was very likely due to more photons being absorbed by the narrower bandgap GaInAsSb material in our case. The $\mathrm{V}_{\text {oc }}$ from the TPV on GaAs was $0.074 \mathrm{~V}$, compared with $0.111 \mathrm{~V}$ from the reference cell. The FF from these two cells was 33\% and 37\% respectively. Both the $\mathrm{V}_{\text {oc }}$ and FF values were clearly lower than the GaSb TPV [11]. The $\mathrm{J}_{0}$ of the TPVs would increase exponentially with narrowing material bandgap, which can the major reason for the lower $\mathrm{V}_{\mathrm{oc}}$ of GaInAsSb TPVs compared with GaSb TPVs. The results from these two tests in Fig. 5a and b are summarized in Table 1.

The GaInAsSb TPVs were also tested under illumination from a quartz halogen $(\mathrm{QH})$ lamp. By changing the distance between the cell and the lamp, the incident power density on the TPVs can be varied by more than two orders of magnitude. The $\mathrm{J}_{\mathrm{sc}}$ versus $\mathrm{V}_{\text {oc }}$ relation was shown in Fig. $6 \mathrm{c}$ for the TPV on GaAs and the reference cell. Interestingly, for the same $J_{s c}$, the difference in $V_{o c}$ values of these two cells stayed almost constant at $40 \mathrm{meV}$. For both devices, a linear relation can be observed between $\ln \left(\mathrm{J}_{\mathrm{sc}}\right)$ and $\mathrm{V}_{\mathrm{oc}}$, in agreement with the results of Dashiell et al. [15]. From the two straight lines in Fig. $6 \mathrm{c}$ we can obtain the ideality factor, $n=1.1$ for both cells, indicating the diffusion current is the major contribution for the reverse dark current in both devices. By extending the two fitting lines to $\mathrm{V}_{\mathrm{oc}}=0$ $\mathrm{V}$, the $\mathrm{J}_{0}$ value was estimated to be $1 \mathrm{~mA} / \mathrm{cm}^{2}$ for the TPV on GaAs, compared with $0.3 \mathrm{~mA} / \mathrm{cm}^{2}$ for the reference cell. This is in good agreement with the dark J-V plots in Fig. 5a showing slightly higher current density from the TPV on GaAs than the reference cell under reverse bias. It is worth noting that the measured $\mathrm{J}_{0}$ values for the two devices lie within the range reported by Mauk et al. for $0.5 \mathrm{eV}$ 
bandgap materials [43], but were still higher than the best values for GaInAsSb TPVs $\left(<0.1 \mathrm{~mA} / \mathrm{cm}^{2}\right)$ [15]. We note that the lack of a wide bandgap barrier and BSF layer in our TPV structure could be a major reason for the higher $\mathrm{J}_{0}$. In addition, it can also be noticed on Fig. $6 c$ that for $\mathrm{J}_{\mathrm{sc}}>0.2 \mathrm{~A} / \mathrm{cm}^{2}$, the $\mathrm{V}_{\mathrm{oc}}$ values started to deviate from the linear fits for both devices. To achieve higher $\mathrm{J}_{\mathrm{sc}}$, the cells needed to be mounted closer to the lamp, which was likely to heat the TPVs. As was demonstrated in our previous work [44], higher cell temperature can have a big impact on the reduction of $V_{\text {oc }}$ due to the increase in $\mathrm{J}_{0}$.

\subsection{Quantum efficiency}

The measured EQE curves of the GaInAsSb TPV on GaAs and the reference TPV are plotted in Fig. 7. The peak EQE value reached $62 \%$ at around $2.3 \mu \mathrm{m}$ for the TPV on GaAs, very close to the reference cell in the plot, which falls in the range of the highest reported EQE's from GaInAsSb TPVs without anti-reflection (AR) coating [15]. In the spectral range of $1.2-2.3 \mu \mathrm{m}$, the EQE from the TPV on GaAs was only lower than the reference cell by about $4 \%$ on average. This indicates that the metamorphic buffer layer has suppressed the TD density in the cell to a low enough range, so that the remaining dislocations had very little effect on the EQE. The slightly lower EQE from the TPV on GaAs was also in good agreement with its lower $\mathrm{J}_{\mathrm{sc}}$ values in Table 1. On these two EQE curves, clear cut-offs can be observed, although the TPV on GaAs exhibited a cut-off at around $2.5 \mu \mathrm{m}$, about $100 \mathrm{~nm}$ longer in wavelength than the reference cell. This was caused by the small compositional differences of the GaInAsSb material from the MBE growth. The slightly narrower material bandgap of the TPV on GaAs may also partly contribute to its higher $J_{\mathrm{sc}}$ and lower $\mathrm{V}_{\mathrm{oc}}$ compared with the reference cell [15]. The reflectance of the $p$-GaSb material on top of the two cells was calculated by taking into account the effects of doping [45], which is plotted as the green curve in Fig. 7. The IQE curves were then obtained from the EQE and reflectance data, also shown in Fig. 7 as the dashed curves. The peak values of about 92\% for both cells are also among the highest IQE values of GaInAsSb TPVs reported in the literature.

In the steel industry, a huge amount of steel is constantly exposed to the atmosphere at around $1127{ }^{\circ} \mathrm{C}$ $(1400 \mathrm{~K})[46]$. Using the measured EQE data in Fig. 7, It can be calculated that the TPV on GaAs can generate $\mathrm{a} \mathrm{J}_{\mathrm{sc}}$ of $6.97 \mathrm{~A} / \mathrm{cm}^{2}$ when mounted in front of the $1400 \mathrm{~K}$ blackbody source, while the reference cell can produce a $\mathrm{J}_{\mathrm{sc}}$ of $6.67 \mathrm{~A} / \mathrm{cm}^{2}$. Assuming the linear relation between $\ln \left(\mathrm{J}_{\mathrm{sc}}\right)$ and $\mathrm{V}_{\mathrm{oc}}$ in Fig. $6 \mathrm{c}$ can still hold true at higher illumination, the $\mathrm{V}_{\text {oc }}$ from the TPV on GaAs and the reference cell will be 0.254 $\mathrm{V}$ and $0.293 \mathrm{~V}$ respectively. If both cells' FF values stay the same as under the $800{ }^{\circ} \mathrm{C} \mathrm{Si}_{3} \mathrm{~N}_{4}$ emitter, the power output from the reference cell can be extrapolated as $1.04 \mathrm{~W} / \mathrm{cm}^{2}$, and $0.81 \mathrm{~W} / \mathrm{cm}^{2}$ from the TPV on GaAs, which is almost the same as the commercial GaSb TPV produced by JX Crystals when tested under a $1200{ }^{\circ} \mathrm{C}$ source $\left(0.82 \mathrm{~W} / \mathrm{cm}^{2}\right)$ [47], but on an inexpensive substrate. 


\section{Conclusions}

The design and development of an advanced metamorphic buffer layer has enabled us to demonstrate a TPV with narrow bandgap GaInAsSb integrated on a cost-effective GaAs substrate, which has almost the same performance characteristics compared with a lattice-matched InGaAsSb TPV on GaSb. The buffer layer region contained a combination of an IMF array and $\mathrm{Ga}_{0.83} \mathrm{In}_{0.17} \mathrm{Sb} / \mathrm{GaSb}$ DFLs. High resolution TEM images and GPA analysis revealed clear misfit arrays, which helped to bind some of the TDs near the GaSb/GaAs interface. The remaining TDs in the buffer region were effectively suppressed by the DFL regions. ECCI measurements indicated the TD density in the GaInAsSb region was reduced to $\sim 10^{6} \mathrm{~cm}^{-2}$. The TPV on GaAs and the reference cell exhibited very similar dark J-V curves, and the series resistance-area product was $49 \mathrm{~m} \Omega \cdot \mathrm{cm}^{2}$ for the TPV on GaAs, compared with 61 $\mathrm{m} \Omega \cdot \mathrm{cm}^{2}$ for the reference cell. However, the $1 / \mathrm{R}_{0} \mathrm{~A}$ versus $\mathrm{P} / \mathrm{A}$ analysis indicated the sidewall resistivity of the TPV on GaAs $(1.79 \mathrm{k} \Omega \cdot \mathrm{cm})$ was still not as good as the reference cell $(2.84 \mathrm{k} \Omega \cdot \mathrm{cm})$, suggesting a lower shunt resistance for the device on GaAs. The performance of the two TPVs was characterized using an $800{ }^{\circ} \mathrm{C} \mathrm{Si}_{3} \mathrm{~N}_{4}$ emitter, as well as a solar simulator in 1 sun (AM 1.5 condition). In both cases, the $\mathrm{J}_{\mathrm{sc}}$ from TPV on GaAs was very close to the refence cell, and the $\mathrm{V}_{\text {oc }}$ was about $40 \mathrm{meV}$ lower than the reference cell. The $J_{s c}$ versus $V_{\text {oc }}$ measurements indicated the $J_{0}$ of the TPV on GaAs $\left(1 \mathrm{~mA} / \mathrm{cm}^{2}\right)$ was still higher than the reference cell $\left(0.3 \mathrm{~mA} / \mathrm{cm}^{2}\right)$, which could be the major reason for its lower $\mathrm{V}_{\mathrm{oc}}$ and FF. The higher $\mathrm{J}_{0}$ from the device on GaAs was likely to be caused by the remaining TDs. The peak EQE of the TPV on GaAs exceeded 60\% and the peak IQE was 92\%, which are the highest ever reported for a GaInAsSb TPV grown on GaAs, and lies in the same range as that for GaInAsSb TPV grown lattice matched on GaSb. On average, the EQE and IQE values of the metamorphic TPV on GaAs were only about $4 \%$ lower than the reference cell. It gives a clear indication that the TD density in the cell was reduced low enough, so that they had a very small impact on the quantum efficiency. This metamorphic buffer layer technique can enable high quantum efficiency GaInAsSb TPVs to be grown on GaAs substrates, which will help to significantly reduce the cost of large area TPV production for waste heat recovery applications.

\section{Acknowledgements}

Financial support for this work was provided by the EPSRC grant (No.:EP/P012035/1). The underlying data in this paper is available from http://dx.doi.org/10.17635/lancaster/researchdata/243. 


\section{References}

[1] H. Daneshvar, R. Prinja, N.P. Kherani, Thermophotovoltaics: Fundamentals, challenges and prospects, Appl. Energy. 159 (2015) 560-575.

[2] C. Ferrari, F. Melino, M. Pinelli, P.R. Spina, M. Venturini, Overview and status of thermophotovoltaic systems, Energy Procedia. 45 (2014) 160-169.

[3] W.R. Chan, P. Bermel, R.C.N. Pilawa-Podgurski, C.H. Marton, K.F. Jensen, J.J. Senkevich, J.D. Joannopoulos, M. Soljacic, I. Celanovic, Toward high-energy-density, high-efficiency, and moderate-temperature chip-scale thermophotovoltaics., Proc. Natl. Acad. Sci. U. S. A. 110 (2013) 5309-14.

[4] A. Datas, C. Algora, Global optimization of solar thermophotovoltaic systems, Prog. Photovolt Res. Appl. 21 (2013) 1040-1055.

[5] A. Datas, A. Martí, Thermophotovoltaic energy in space applications: Review and future potential, Sol. Energy Mater. Sol. Cells. 161 (2017) 285-296.

[6] E. Shoaei, Performance assessment of thermophotovoltaic application in steel industry, Sol. Energy Mater. Sol. Cells. 157 (2016) 55-64.

[7] B. Bitnar, W. Durisch, D. Grutzmacher, J.C. Mayor, C. Muller, F. Von Roth, J.A.A. Selvan, H. Sigg, H.R. Tschudi, J. Gobrecht, A TPV system with silicon photocells and a selective emitter, Conf. Rec. IEEE Photovolt. Spec. Conf. (2000) 1218-1221.

[8] A. Krier, M. Yin, A.R.J. Marshall, M. Kesaria, S.E. Krier, S. McDougall, W. Meredith, A.D. Johnson, J. Inskip, A. Scholes, Low bandgap mid-infrared thermophotovoltaic arrays based on InAs, Infrared Phys. Technol. 73 (2015) 126-129.

[9] M. Tan, L. Ji, Y. Wu, P. Dai, Q. Wang, K. Li, T. Yu, Y. Yu, S. Lu, H. Yang, Investigation of InGaAs thermophotovoltaic cells under blackbody radiation, Appl. Phys. Express. 7 (2014) 96601.

[10] A.W. Bett, O. V. Sulima, GaSb photovoltaic cells for applications in TPV generators, Semicond. Sci. Technol. 18 (2003) S184-S190. doi:10.1088/0268-1242/18/5/307.

[11] L. Tang, H. Ye, J. Xu, A novel zinc diffusion process for the fabrication of high-performance GaSb thermophotovoltaic cells, Sol. Energy Mater. Sol. Cells. 122 (2014) 94-98.

[12] H.K. Choi, C.A. Wang, G.W. Turner, M.J. Manfra, D.L. Spears, G.W. Charache, L.R. Danielson, D.M. Depoy, High-performance GaInAsSb thermophotovoltaic devices with an AlGaAsSb window, Appl. Phys. Lett. 71 (1997) 3758. 
[13] C.A. Wang, H.K. Choi, S.L. Ransom, G.W. Charache, L.R. Danielson, D.M. DePoy, Highquantum-efficiency $0.5 \mathrm{eV}$ GaInAsSb/GaSb thermophotovoltaic devices, Appl. Phys. Lett. 75 (1999) 1305-1307.

[14] G.W. Charache, P.F. Baldasaro, L.R. Danielson, D.M. DePoy, M.J. Freeman, C.A. Wang, H.K. Choi, D.Z. Garbuzov, R.U. Martinelli, V. Khalfin, S. Saroop, J.M. Borrego, R.J. Gutmann, InGaAsSb thermophotovoltaic diode: Physics evaluation, J. Appl. Phys. 85 (1999) $2247-2252$.

[15] M.W. Dashiell, J.F. Beausang, H. Ehsani, G.J. Nichols, D.M. Depoy, L.R. Danielson, P. Talamo, K.D. Rahner, E.J. Brown, S.R. Burger, P.M. Fourspring, W.F. Topper, P.F. Baldasaro, C.A. Wang, R.K. Huang, M.K. Connors, G.W. Turner, Z.A. Shellenbarger, G. Taylor, J. Li, R. Martinelli, D. Donetski, S. Anikeev, G.L. Belenky, S. Luryi, Quaternary InGaAsSb thermophotovoltaic diodes, IEEE Trans. Electron Devices. 53 (2006) 2879-2888.

[16] L.M. Fraas, J.E. Samaras, L.M. Minkin, TPV cylindrical generator for home cogeneration. US patent 6,489,553 B1, US 6,489,553 B1, 2002.

[17] L.M. Fraas, J.E. Avery, TPV cylindrical generator for how cogeneration using low nox radiatant tube burner. US patent 7,196,263 B2, 2007.

[18] Y. Wang, X. Zhang, X. Zhang, N. Chen, Electricity generation from thermal irradiation governed by GaSb active layer, Renew. Energy. 48 (2012) 231-237.

[19] Y. Wang, Y. Lou, Radiant thermal conversion in $0.53 \mathrm{eV} \mathrm{GaInAsSb}$ thermophotovoltaic diode, Renew. Energy. 75 (2015) 8-13.

[20] L. Tang, L.M. Fraas, Z. Liu, C. Xu, X. Chen, The theoretical performance of GaInAsSb and GaSb cells versus IR emitter temperature in thermophotovoltaic systems, IEEE Trans. Electron Devices. 63 (2016) 3591-3598.

[21] A.Y. Liu, R.W. Herrick, O. Ueda, P.M. Petroff, A.C. Gossard, J.E. Bowers, Reliability of InAs/GaAs quantum dot lasers epitaxially grown on silicon, IEEE J. Sel. Top. Quantum Electron. 21 (2015) 1900708.

[22] S.Y. Karpov, Y.N. Makarov, Dislocation effect on light emission efficiency in gallium nitride, Appl. Phys. Lett. 81 (2003) 4721-4723.

[23] R.M. France, J.F. Geisz, M.A. Steiner, B. To, M.J. Romero, W.J. Olavarria, R.R. King, Reduction of crosshatch roughness and threading dislocation density in metamorphic GaInP buffers and GaInAs solar cells, J. Appl. Phys. 111 (2012) 103528. 
[24] S. Chen, W. Li, J. Wu, Q. Jiang, M. Tang, S. Shutts, S.N. Elliott, A. Sobiesierski, A.J. Seeds, I. Ross, P.M. Smowton, H. Liu, Electrically pumped continuous-wave III-V quantum dot lasers on silicon, Nat. Photonics. 10 (2016) 307-311.

[25] Y. Wang, P. Ruterana, L. Desplanque, S. El Kazzi, X. Wallart, Strain relief at the GaSb/GaAs interface versus substrate surface treatment and AlSb interlayers thickness, J. Appl. Phys. 109 (2011) 23509.

[26] S. Huang, G. Balakrishnan, D.L. Huffaker, Interfacial misfit array formation for GaSb growth on GaAs, J. Appl. Phys. 105 (2009) 103104. doi:10.1063/1.3129562.

[27] I. Vurgaftman, J.R. Meyer, Band parameters for III-V compound semiconductors and their alloys, J. Appl. Phys. 89 (2001) 5815-5875. doi:10.1063/1.1368156.

[28] M.J. Hÿtch, E. Snoeck, R. Kilaas, Quantitative measurement of displacement and strain fields from HREM micrographs, Ultramicroscopy. 74 (1998) 131-146.

[29] S. Abedrabbo, Emissivity Measurements and Modelling of Silicon Related Materials and Structures [dissertation], New Jersey’s Science \& Technology University, 1998.

[30] T. Ward, A.M. Sánchez, M. Tang, J. Wu, H. Liu, D.J. Dunstan, R. Beanland, Design rules for dislocation filters, J. Appl. Phys. 116 (2014) 63508.

[31] I. George, F. Becagli, H.Y. Liu, J. Wu, M. Tang, R. Beanland, Dislocation filters in GaAs on Si, Semicond. Sci. Technol. 30 (2015) 114004.

[32] Y. Wan, Q. Li, A.Y. Liu, A.C. Gossard, J.E. Bowers, E.L. Hu, K.M. Lau, Optically pumped $1.3 \mu \mathrm{m}$ room-temperature InAs quantum-dot micro-disk lasers directly grown on (001) silicon, Opt. Lett. 41 (2016) 1664.

[33] J. Wu, Q. Jiang, S. Chen, M. Tang, Y.I. Mazur, Y. Maidaniuk, M. Benamara, M.P. Semtsiv, W.T. Masselink, K.A. Sablon, G.J. Salamo, H. Liu, Monolithically integrated InAs/GaAs quantum dot mid-infrared photodetectors on silicon substrates, ACS Photonics. 3 (2016) 749753.

[34] M. Mehta, A. Jallipalli, J. Tatebayashi, M.N. Kutty, A. Albrecht, G. Balakrishnan, L.R. Dawson, D.L. Huffaker, S. Member, Room-temperature operation of buffer-free GaSb AlGaSb quantum-well diode lasers grown on a GaAs platform emitting at $1.65 \mu \mathrm{m}$, IEEE Photonics Technol. Lett. 19 (2007) 1628-1630.

[35] M. Mehta, G. Balakrishnan, S. Huang, A. Khoshakhlagh, P. Patel, M.N. Kutty, L.R. Dawson, D.L. Huffaker, GaSb quantum-well-based "buffer-free" vertical LED monolithically 
embedded within a GaAs cavity using interfacial misfit arrays, Appl. Phys. Lett. 89 (2007) 211110.

[36] E. Plis, J.B. Rodriguez, G. Balakrishnan, Y.D. Sharma, H.S. Kim, T. Rotter, S. Krishna, Midinfrared InAs/GaSb strained layer superlattice detectors with $\mathrm{nBn}$ design grown on a $\mathrm{GaAs}$ substrate, Semicond. Sci. Technol. 25 (2010) 85010.

[37] B.C. Juang, R.B. Laghumavarapu, B.J. Foggo, P.J. Simmonds, A. Lin, B. Liang, D.L. Huffaker, GaSb thermophotovoltaic cells grown on GaAs by molecular beam epitaxy using interfacial misfit arrays, Appl. Phys. Lett. 106 (2015) 111101.

[38] C. Trager-Cowan, F. Sweeney, P.W. Trimby, A.P. Day, A. Gholinia, N.H. Schmidt, P.J. Parbrook, A.J. Wilkinson, I.M. Watson, Electron backscatter diffraction and electron channeling contrast imaging of tilt and dislocations in nitride thin films, Phys. Rev. B. 75 (2007) 85301.

[39] Z. Shi, L. Wang, Y. Cui, H. Liu, H. Tian, W. Wang, H. Chen, Suppressing the spread length of threading dislocations in $\mathrm{AlSb} / \mathrm{GaSb}$ superlattice grown on (001) InP substrate, Appl. Phys. A Mater. Sci. Process. 115 (2014) 1239-1243.

[40] W. Chan, R. Huang, C. Wang, J. Kassakian, J. Joannopoulos, I. Celanovic, Modeling lowbandgap thermophotovoltaic diodes for high-efficiency portable power generators, Sol. Energy Mater. Sol. Cells. 94 (2010) 509-514.

[41] L.M. Giovane, H.C. Luan, A.M. Agarwal, L.C. Kimerling, Correlation between leakage current density and threading dislocation density in SiGe p-i-n diodes grown on relaxed graded buffer layers, Appl. Phys. Lett. 78 (2001) 541-543.

[42] H. Zogg, K. Alchalabi, D. Zimin, K. Kellermann, W. Buttler, Two-dimensional monolithic lead chalcogenide infrared sensor array on silic on read-out chips and noise mechanisms, IEEE Trans. Electron Devices. 50 (2003) 209-214.

[43] M.G. Mauk, V.M. Andreev, GaSb-related materials for TPV cells, Semicond. Sci. Technol. 18 (2003) S191.

[44] Q. Lu, X. Zhou, A. Krysa, A. Marshall, P. Carrington, C.H. Tan, A. Krier, InAs thermophotovoltaic cells with high quantum efficiency for waste heat recovery applications below $1000{ }^{\circ} \mathrm{C}$, Sol. Energy Mater. Sol. Cells. 179 (2018) 334-338.

[45] B.R. Bennett, R.A. Soref, S. Member, J.A.D.E.L. Alamo, Carrier-Induced Change in Refractive Index of InP , GaAs , and InGaAsP, IEEE J. Quantum Electron. 26 (1990) 113- 
122.

[46] L.M. Fraas, Economic potential for thermophotovoltaic electric power generation in the steel industry, 2014 IEEE 40th Photovolt. Spec. Conf. PVSC 2014. (2014) 766-770.

[47] http://jxcrystals.com/GaSb/4sale5.pdf 


\begin{tabular}{|l|l|l|l|l|}
\hline \multirow{2}{*}{} & \multicolumn{3}{|l|}{$800{ }^{\circ} \mathrm{C} \mathrm{Si}_{3} \mathrm{~N}_{4}$} & \multicolumn{2}{l|}{1 sun AM 1.5 } \\
\cline { 2 - 5 } & TPV on GaAs & Reference cell & TPV on GaAs & Reference cell \\
\hline $\mathrm{J}_{\mathrm{sc}}\left(\mathrm{A} / \mathrm{cm}^{2}\right)$ & 0.98 & 1.04 & 0.035 & 0.040 \\
\hline $\mathrm{V}_{\text {oc }}(\mathrm{V})$ & 0.178 & 0.214 & 0.074 & 0.111 \\
\hline FF & $46 \%$ & $53 \%$ & $33 \%$ & $37 \%$ \\
\hline
\end{tabular}

Table 1. Performance comparisons between the GaInAsSb TPV on GaAs and the reference cell on GaSb. The $800{ }^{\circ} \mathrm{C} \mathrm{Si}_{3} \mathrm{~N}_{4}$ has $\lambda_{\mathrm{pk}} \sim 2.6 \mu \mathrm{m}$, while the solar simulator has $\lambda_{\mathrm{pk}} \sim 0.6 \mu \mathrm{m}$. 


\section{Figure captions}

Figure 1. Schematic illustration of the GaInAsSb TPV on GaAs substrate.

Figure 2. (a) Bright field cross-section TEM image of the buffer region on GaAs substrate. High resolution TEM images of (b) the top DFL region, and (c) the $\mathrm{GaSb} / \mathrm{GaAs}$ interface showing the periodic IMF array. (d) The $x x$ component of the strain on the GaSb/GaAs interface from the GPA measurement.

Figure 3. $\omega-2 \theta$ XRD plot of the buffer region (redcurve) and the simulated fitting to determine the layer thickness and material composition (blue curve).

Figure 4. Electron channelling contrast image (ECCI) of the surface from the TPV on GaAs showing emerging TDs as bright or dark dots, corresponding to a density of $\sim 10^{6} \mathrm{~cm}^{-2}$.

Figure 5. (a) Dark current density-voltage curves, and (b) The $1 / \mathrm{R}_{0} \mathrm{~A}$ product near zero bias as a function of P/A of the TPV on GaAs and the reference cell on GaSb.

Figure 6. J-V curves from the metamorphic TPV on GaAs and the reference cell when illuminated (a) using an $800{ }^{\circ} \mathrm{C} \mathrm{Si}_{3} \mathrm{~N}_{4}$ emitter, $\lambda_{\mathrm{pk}} \sim 2.7 \mu \mathrm{m}$, and (b) solar simulator; 1 sun AM 1.5 condition, $\lambda_{\mathrm{pk}} \sim 0.6$ $\mu \mathrm{m}$. (c) $\mathrm{J}_{\mathrm{sc}}$ versus $\mathrm{V}_{\mathrm{oc}}$ plot of the two TPVs illuminated using a quartz halogen lamp, $\lambda_{\mathrm{pk}} \sim 0.9 \mu \mathrm{m}$, with varying light intensities.

Figure 7. EQE and IQE curves of the GaInAsSb TPV on GaAs and the reference TPV on GaSb. The green curve illustrates the reflectance of the $\mathrm{p}-\mathrm{GaSb}$. 
Fig. 1

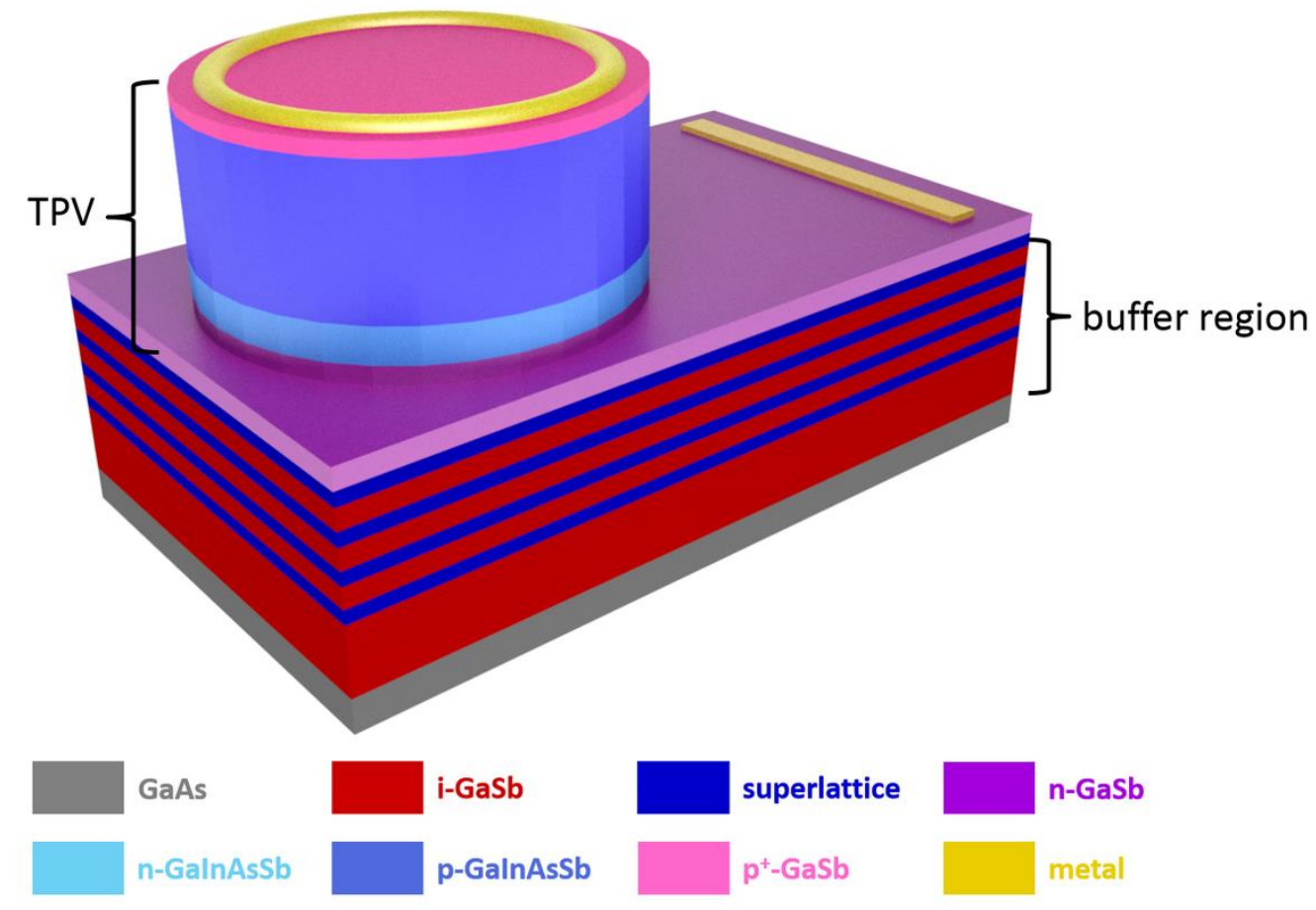

Fig. 2
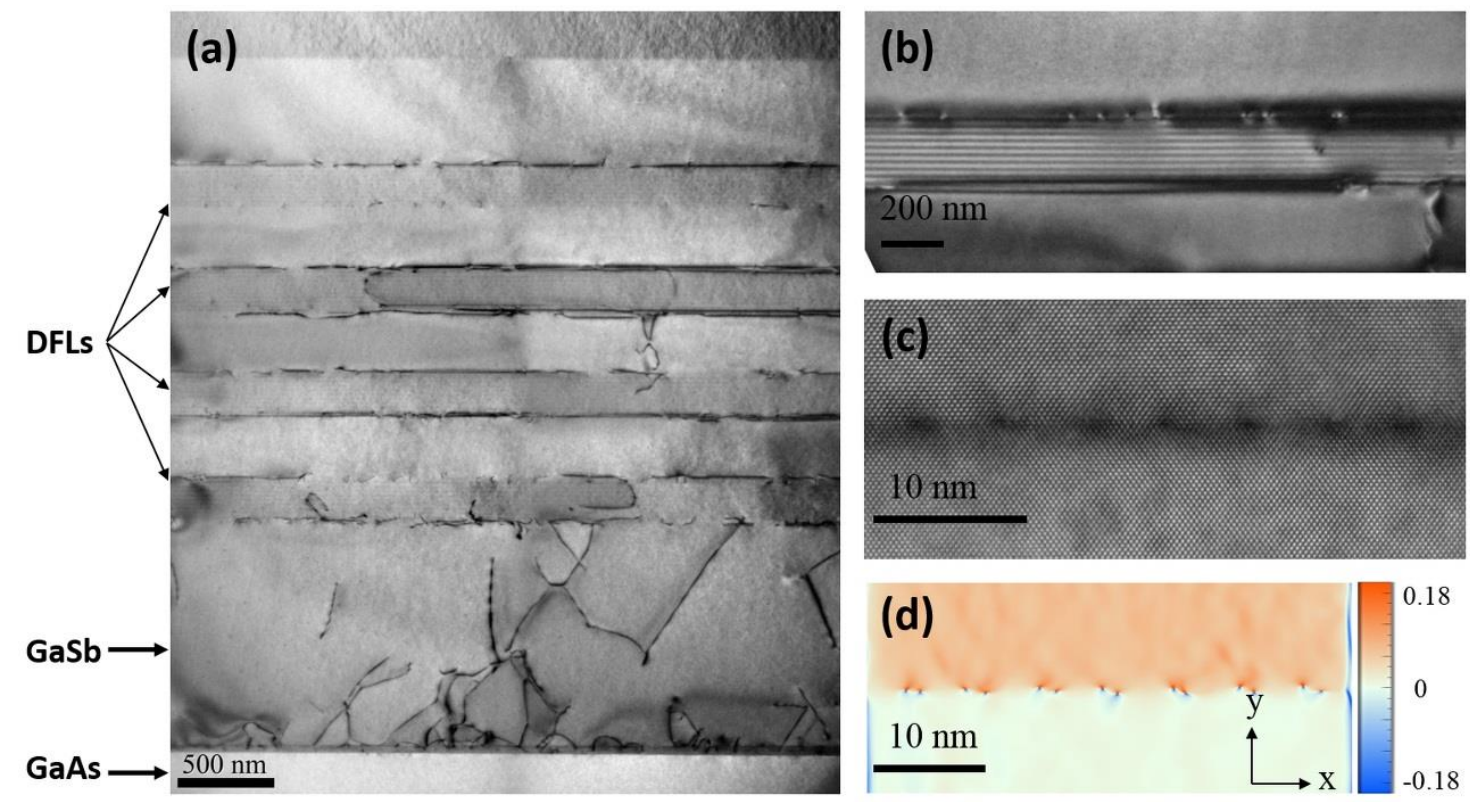
Fig. 3

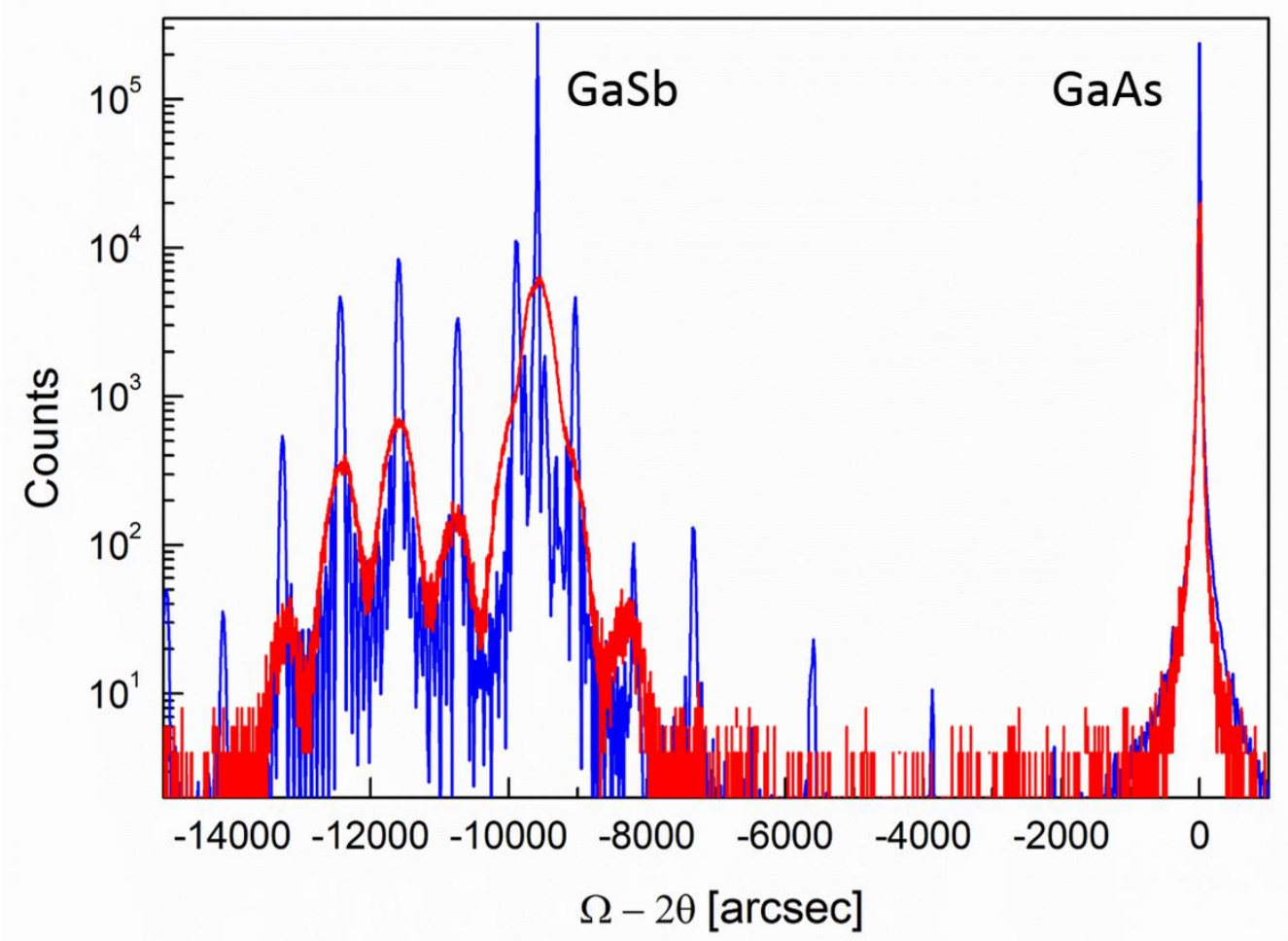

Fig. 4

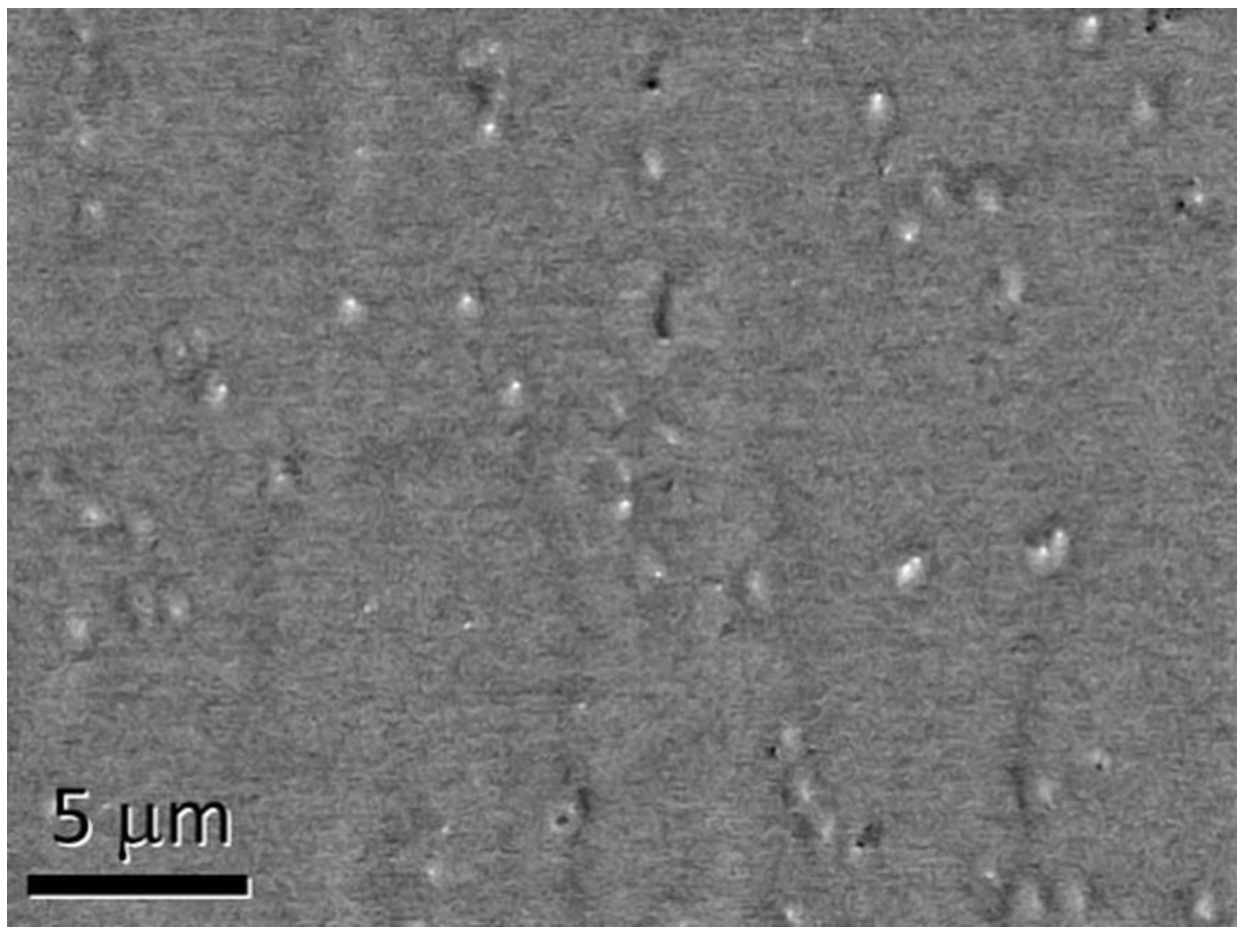


Fig. 5
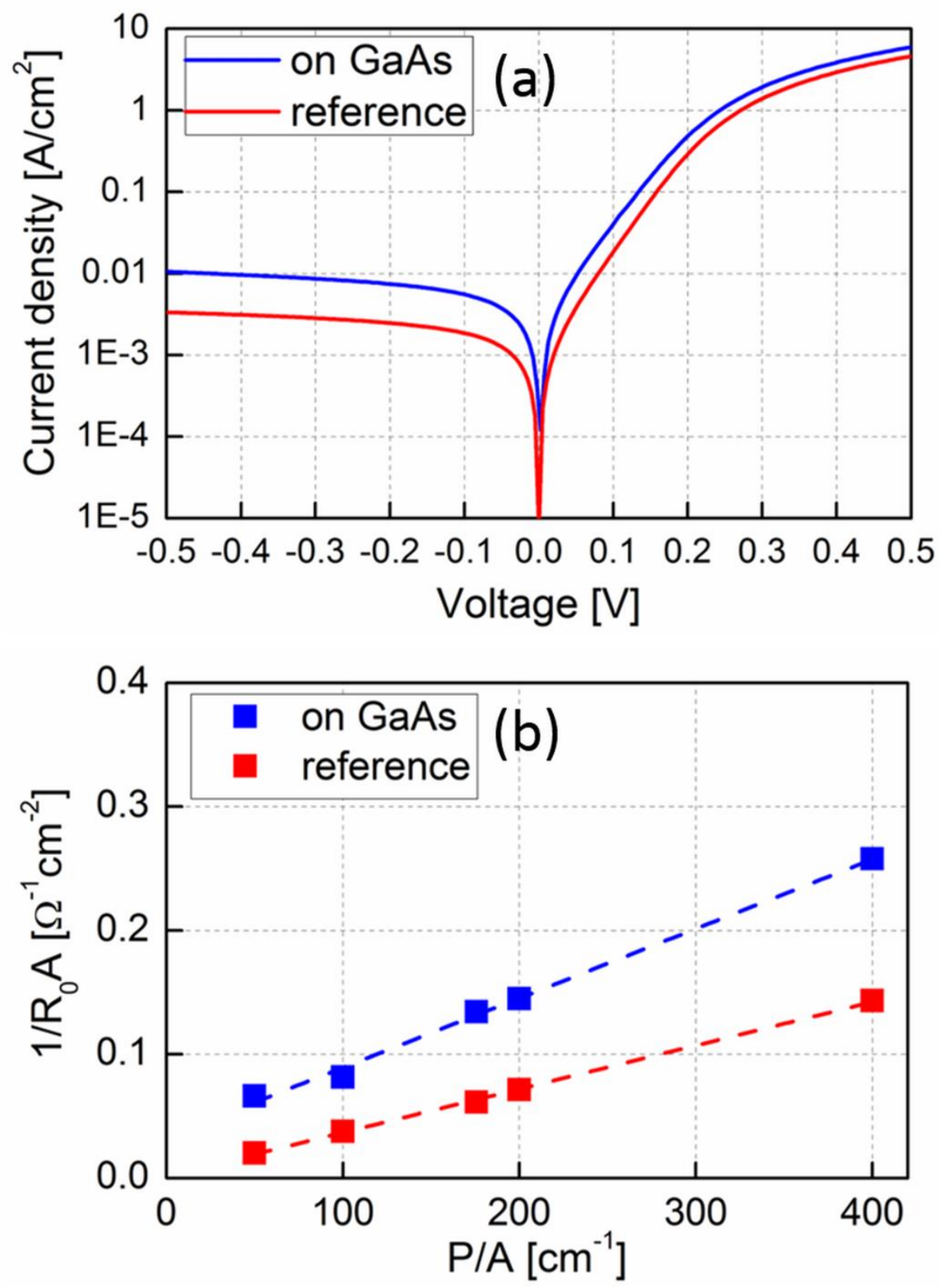
Fig. 6
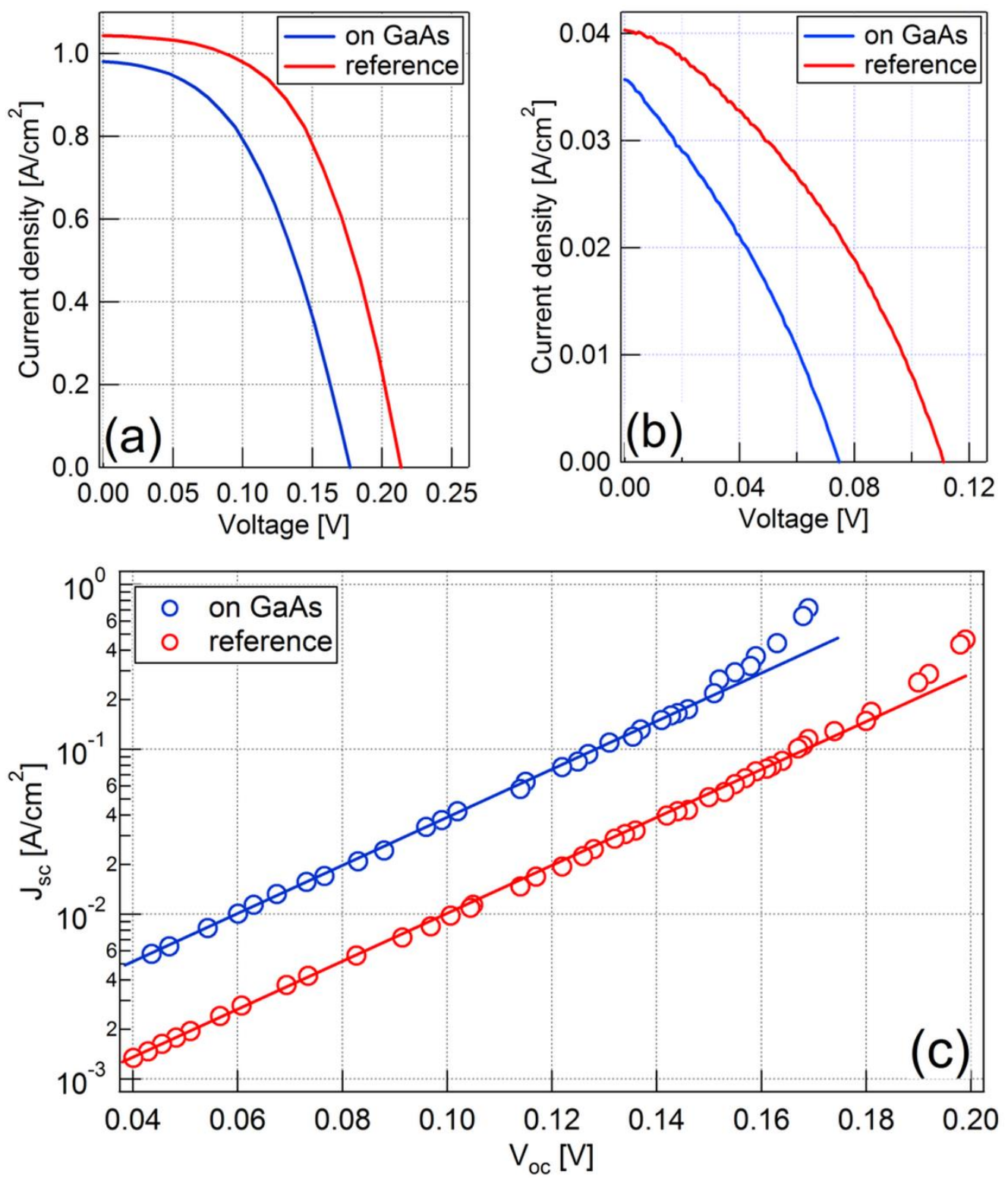
Fig. 7

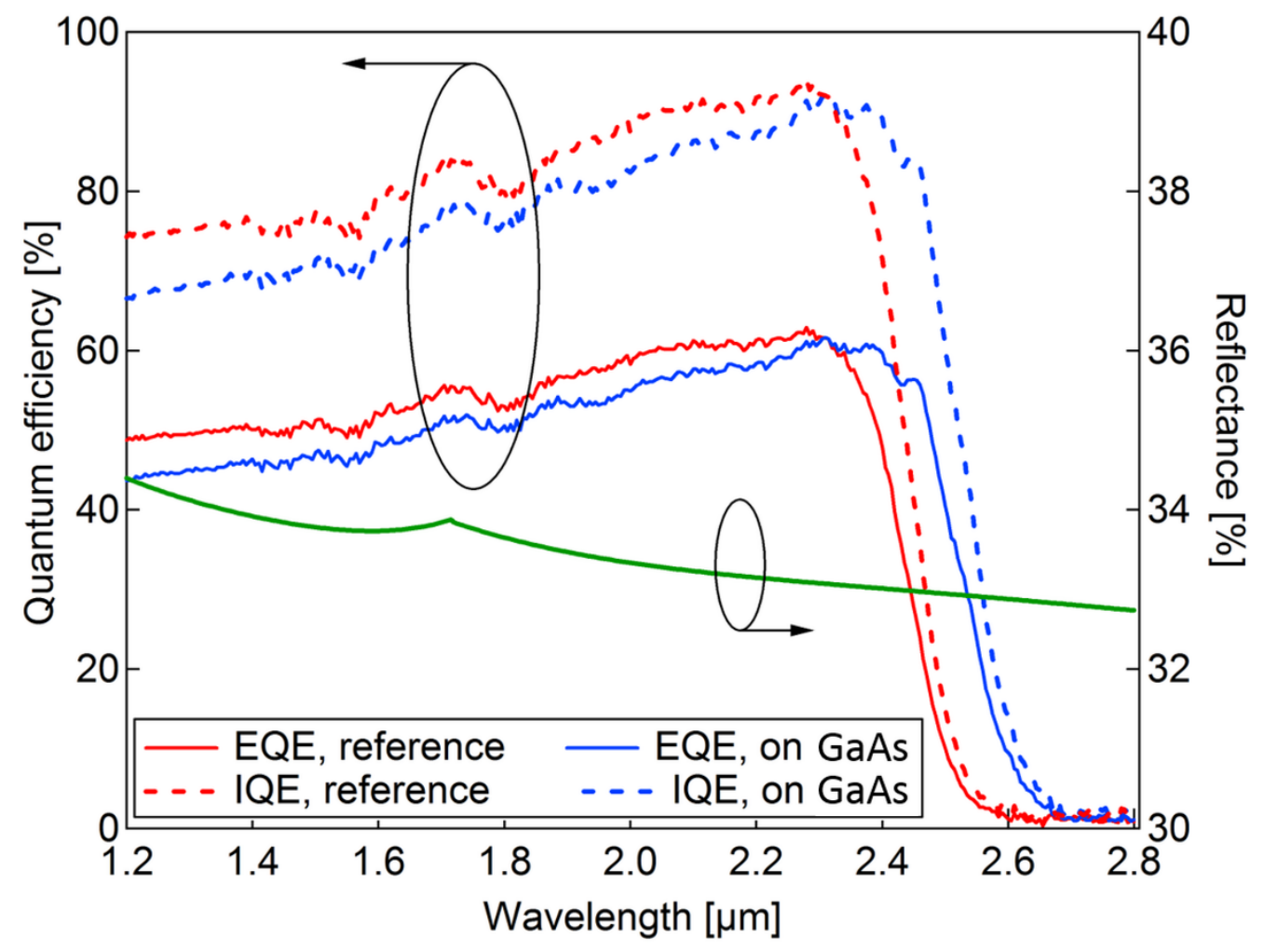

